\title{
Risk perceptions of STIs/HIV and sexual risk behaviours among sexually experienced adolescents in the Northern part of Lao PDR
}

Vanphanom Sychareun ${ }^{1,2^{*}}$, Sarah Thomsen ${ }^{2+}$, Kongmany Chaleunvong ${ }^{3+}$ and Elisabeth Faxelid ${ }^{2 \dagger}$

\begin{abstract}
Background: Young people in Laos are more vulnerable to STIS/HIV due to their sexual risk behaviours, low perceptions of risk and their socio-cultural environments. Perceived risk of contracting STIs/HIV is crucial for the assessment of their risk regarding their actual sexual risk behaviors. Thus, the objective of this paper is to explore perceptions of risk related to STIS/HIV and identify factors associated with this perceived risk among adolescents.

Methods: This was a cross sectional study of sexually experienced adolescents aged 14 to 19 years old in the Luangnamtha province. The multistage sampling techniques were used for selecting 1008 adolescents aged 14-19 years old. Of these, 483 respondents reported having had sexual experience was selected for analysis. Univariate and Logistic regression were performed.

Result: Six per cent of respondents reported ever having had anal sex. Slightly less than two thirds initiated their first sexual intercourse before age 15. Two thirds of the sexually experienced males reported two or more sexual partners during their lifetime with the mean $3.1+3.65$ while only twelve per cent of girls reported this cumulative number of partners. Slightly more than half (57.6\%) regarded themselves to have no risk at all with 17.2 per cent considered themselves to have low risk. Respondents had poor knowledge on STIs/HIV. Factors associated with risk perception of getting STIs were: being male, high level of knowledge about STIs and having had symptoms of STIs in last six months. Perceived risk of getting HIV was significantly associated with being male, having more knowledge about STIs and HIV.

Conclusion: Adolescents in this study engaged in sexual risk behaviours, but they have low perception of risk getting STI/HIV. Socio-demographic factors, knowledge of STIS/HIV, and the level of exposure to STIs were the main determinants of the risk perception of STIS/HIV. Our finding supports the need to target adolescents in Luangnamtha province for HIV prevention intervention by addressing inaccurate perception of risk and increasing their knowledge on STIS/HIV.
\end{abstract}

Keywords: Risk perceptions, Sexual risk behaviors, Luangnamtha province, Lao PDR

\section{Background}

HIV/AIDS is emerging as a potentially serious health issue for Lao PDR, even though, it is currently categorized as a low HIV prevalence country, with an estimated HIV prevalence of $0.2 \%$ [1]. At the mid of 2011,

\footnotetext{
*Correspondence: vsychareun@gmail.com

${ }^{\dagger}$ Equal contributors

${ }^{1}$ Faculty of Postgraduate Studies, University of Health Sciences, Samsenthia Road, P.O.Box 7444, Vientiane, Lao PDR

${ }^{2}$ Division of Global Health (IHCAR), Department of Public Health Sciences, Karolinska Institutet, SE 17177 Stockholm, Sweden

Full list of author information is available at the end of the article
}

the official cumulative number of HIV positive people was 4,272. Of those, 2,736 were living with HIV/AIDS and 1,170 had already died [2]. However, Lao PDR has a high prevalence of sexually transmitted infections (STIs) (1.8\%), especially among most-at-risk population [1]. STIs are the most pervasive infectious diseases confronting adolescents. Strong evidence supports several biological mechanisms through which STIs facilitate HIV transmission by increasing both HIV infectiousness and HIV susceptibility [3]. Thus if the incidence/prevalence of STIs is high in a country, there is a high risk of sexual transmission of HIV [4]. The major mode of STIs including HIV transmission

\section{Biomed Central}


in Lao PDR is heterosexual and the majority of people infected are men aged 20-29 years old [1]. The serious and growing epidemics in several of Lao PDR's neighboring countries, increasing population mobility, both within and across Lao PDR's borders, trafficking of women, girls and boys and improved transportation networks make the country increasingly vulnerable to HIV/AIDS [5].

The Lao National HIV/AIDS strategies 2011-2015 recognize that young people are a particular vulnerable group for HIV infection [6]. Adolescents aged 13 to 19 have been identified as a vulnerable group for acquiring STIs and HIV/AIDS, especially adolescents from ethnic minorities [7-9]. The vulnerability of adolescents to the HIV infection is due to personal [10-12] and socio-cultural factors $[9,13]$. Personal factors include lack of HIV knowledge and widespread misconceptions; limited knowledge of preventive methods, and greater biological susceptibility for girls to STIs/HIV infections and its consequences $[14,15]$. Sexual risk behaviours include initiation of sexual intercourse at an early age, multiple sex partners within a short period, and practice of unsafe sex such as no condom use $[16,17]$ and presence of STI symptoms [18]. Sexual behaviour is dependent upon the social and cultural environment in which one lives, and is influenced by societal sexual norms and practices, and not just self-perceived susceptibility to HIV infection [19]. Socio-cultural factor includes traditional sexual customs such as "Vagina Breakthrough" and "Welcome Guest" for girls and "Open foreskin" for boys, which make them more at risk of STIs including HIV [9]. "Vagina Breakthrough" is a pre-pubertal rite of passage whereby a young girl has penetrative sexual intercourse with an older, sexually mature man. The act of "Vagina Breakthrough" makes a "hole" in the girl's vagina making her sexually mature. Girls who have performed "Breakthrough Vagina" may then participate in the cultural practice of "Welcome Guest" whereby they entertain male visitors to the village by providing massage to the visitors in a small "Welcome Guest" hut. Boys aged 12 and 15 must seek out an older, sexually experienced woman for their first sexual encounter in order to "open" the foreskin and mature into a man.

The Health Belief Model (HBM) identifies the perceived susceptibility or perceived risk, perceived severity, perceived benefits, and perceived barriers as predictor of safer sexual activity [20]. Previous researchers have suggested that there is an association between higher level of sexual risk taking and high level perceived risks of contracting HIV [19,21-23]; however, some researchers have not found any association [24]. Other studies have found that low level of sexual risk-taking results from high levels of perceived risks of contracting HIV [25].

In addition to the HBM, other models of behavioural change have incorporated additional key constructs such as concept of self-efficacy, which is defined as having confidence in one's ability to perform a particular behavior [26-28]. Self-efficacy plays a crucial role in STI/HIV prevention behavior such as using condoms and limiting the number of sexual partners. Positive perception of self-efficacy would be expected to be inversely associated with STIs/HIV risk behaviors.

Perceived peer sexual norms are significant determinant of the spread of STI/HIV/AIDS through the impact of permissive sexual norms on sexual behaviours [29,30]. Peer sexual norms play an important part role in sexual behaviour. Involvement in risky sexual practices was found to be higher among youth who have peers who hold permissive sexual norms [31]. Although social influences, particularly peer norms, seem to be important determinants of sexual initiation, the complex relationship between the different components of peer norms and behavioral change has yet to be clearly elucidated $[32,33]$.

Relatively few studies in Lao PDR have examined adolescent's sexual risk taking behaviors and its association with perceived risk of getting STIs/HIV. Thus, the objective of this paper is to explore perceptions of risk related to STIs/HIV and identify factors associated with this perceived risk among adolescents. Perceived risk of contracting STIs/HIV may have important implications for prevention programs among adolescents from different ethnic groups. This study is significant because it provides insights into the subjective perceptions of risk of STIs/HIV infection in a population identified as a vulnerable to HIV but with whom there has been limited research and situates risk perception within the sociocultural context of northern Lao PDR. This focus is particularly pertinent given that the sexual behaviors of adolescents from ethnic minorities can expose them to the risks of STIs/HIV.

\section{Methods}

\section{Study setting}

The study was carried out in the rural areas of Luangnamtha province in Northern Lao PDR using a community-based sample of adolescents. Luangnamtha province has 32 ethnic groups, occupies an area of 9,325 square kilometers, and has a total population of 145,231 people with 73,873 females. Of the total population, 36,531 belong to the Akha ethnic group [34]. The population structure consists of predominantly young people, with the majority aged 15-30 years [35]. The net enrollment in the lower secondary school in the province is low compared to the national data (15\% versus $28.5 \%$ ) [36].

Long and Sing districts were the target study sites. These districts were selected because there are many different ethnic groups with about half belonging to the Akha ethnic group. There is also high poverty in these districts [37]. In addition, these districts share border with neighboring countries with high STI/HIV prevalence such as 
Myanmar and China (Yunnan province). Many ethnic groups still have some traditional sexual customs that put adolescents at significant risks related to sexual and reproductive health. These cultural beliefs might moderate the way in which STI/HIV is perceived and therefore addressed in that particular context [38].

The first case of HIV in Luangnamtha province was detected in 2004 and the province has emerged as the province with the highest prevalence of reported HIV infection $(0.03 \%)$ in the country. According to the annual report of Luangnamtha Provincial Health Department in 2011, 2769 people have been tested for HIV. Forty-six were HIV positive, 30 lived with HIV/AIDS and 12 deaths had been recorded in Luangnamtha province by the end of 2010 [34]. In addition, the province has a high prevalence of STIs (4.3\%) [1].

\section{Design and participants}

This was a quantitative cross-sectional descriptive study. The estimated sample size yielded 400 males and 650 females based on the standard formula for the population proportion [39]. Two-stage systematic random sampling was employed to recruit the target group into the study. The sampling frame of adolescents aged 14-19 years in the selected villages was prepared from the household enumeration. While the World Health Organization defines adolescents as young people between the ages of 10 and 19 years [40], for the purpose of this study we used the age range of 14-19 as most adolescents in the target population begin sexual relations between 12-15 years [9,41]. First, the sampling list of villages in the two districts was prepared, then 40 villages were randomly selected with probability proportional to size of each district. Secondly, from each selected village, unmarried adolescents aged 1419 years were systematically randomly selected from the constructed sampling frame with probability proportional to size of the villages. A total of 1050 adolescents were approached and 1008 were enrolled into the study, thus four per cent did not participate. The primary reasons for non-participation were being absent at the time of interview. Respondents were asked the following questions: a) Have you ever had sexual intercourse? b) Have you ever had vaginal intercourse? c) "Have you ever had anal intercourse? Vaginal sex was defined as penile vagina penetrative sexual intercourse; oral sex referred to involving penetration of the mouth by the penis or oral penetration of the vulva or vagina; and anal sex was defined as penetration of the anus by the penis. Then, they were classified as having sexual experience if they answered "yes" to one of the above questions. Among 1008 respondents, 486 were sexually experienced; however, 3 questionnaires were incomplete, thus, the sample for this analysis was restricted to the 483 adolescents who reported having had sexual experience.

\section{Measures}

Respondents were asked about socio-demographic factors, psychosocial factors (self-efficacy and peer sexual norms), knowledge about STIs, including HIV, and markers of risky sexual behaviors (early age at first sexual intercourse, number of sex partners, unprotected sexual intercourse, and alcohol and drug use) (Additional file 1). Background characteristics of respondents included sex, age, education, currently going to school, ethnicity, and living arrangement. Ethnicity was measured by respondent's identification as Lao, Khamu, Akha, Hmong, or Yao. Then, this variable was recorded as Akha and Non Akha. Sociocultural practices such as experience of "Vagina Breakthrough, 'Welcome guest' for girls and "Open foreskin" for boys were also asked. Risk factors for example, knowledge of STIs and HIV, practices such as condom use during the last 6 months and having STIs symptoms were identified as being important in the literature [14-18].

The section regarding STIs knowledge included whether the respondents had heard of STIs, major source of STIs information, STIs symptoms, transmission route, and consequences of untreated STIs. The correct response was coded 1 and each incorrect or non-response was coded 0 . All 12 STIs questions were summed up with higher score indicating higher level of knowledge of STIs. The internal consistency of the scale Kuder-Richardson-20 (KR-20) in this sample was 0.67 .

The section related to awareness of HIV included questions whether the respondent had heard of HIVAIDS and the major source of HIV information. We used the brief HIV knowledge Questionnaire (HIVKQ) $[42,43]$ to assess knowledge regarding transmission and prevention of HIV which was modified according to the Lao context. Respondents answered to 8 items using true/false. Responses were scored 1 if correct and 0 if not. In total, therefore, scores on the HIV knowledge range from 0 to 8 . All 8 HIV questions were summed up with higher score indicating higher level of knowledge of HIV. The internal consistency of the scale was KR-20 coefficient $=.65$.

Self-efficacy was measured using a scale score on abstinence, condom use, and communication with partner. This scale was constructed from a previously validated scale of self-efficacy [22,44] and included 15 items. Respondents rated each item using a 5 point scale ranging from not at all to very likely, with increasing scores indicating higher self-efficacy. The internal consistency of the scores on the 5-item scale, as measured using Cronbach's alpha coefficient was .87 .

The perceived peer sexual norms questionnaire, a selfreported measure, had five items originally developed in English by previous researchers [30,45]. The scale assessed what adolescents believed their friends thought about engaging in sexual risk behaviors. The adolescents were asked to indicate the degree to which an item described 
what they believed on a five-point Likert scale ranging from 0 (none of my friends) to 5 (all of my friends) engaged in sexual risk behaviors (having multiple sexual partners, no condom use, selling sex, having STIs, and using illicit drugs). This procedure is consistent with established methodologies for assessing perceptions of friends' sexual behaviour [46]. The total score ranged from 0 to 14, with a Cronbach's alpha coefficient of .79. Higher score indicated perception of more permissive sexual peer norms.

To determine the level of risk perception, participants were asked how afraid they were of getting STIs and HIV and the chance of contracting STIs and HIV. The response was categorized as $0=$ "no chance" or $1=$ "small chance" of contracting the disease and were classified as having low risk perception. Those reporting their risk as $3=$ "somewhat" chance were classified as having moderate risk perception and those reporting or 4 = "high" chance or 5-"very high chance" were coded as "high risk".

Sexual behaviors were obtained from the sexually experienced adolescents who reported ever having had sex. Questions included age at first sex, numbers and type of sexual partners to date, sexual experiences during the last six months prior to the interview, condom use at the first sex and during the last six months preceding the interview. Finally the respondents reported experience of having STI symptoms during the last six and 12 months.

\section{Data collection}

Experienced interviewers from the Faculty of Postgraduate Studies and Research underwent three days training about the objectives of the research project, data collection process, sampling procedures, and the content of the questionnaire. The questionnaire was translated from English into the local language Lao. In addition, young Akha translators were recruited to support data collection where Akha respondents were not comfortable in speaking Lao. Interviewers were matched with the sex of respondents and privacy was to ensure during interview.

\section{Data analysis}

Data entry was done using EPI-INFO. The data were analyzed by using SPSS version 10.0 and STATA. Univariate analysis was performed by presenting frequencies and percentages for categorical variables and means ( \pm Standard Deviation) for continuous variables. Results from male and female adolescents were compared. Unadjusted and adjusted OR with 95\% confidence intervals (95\% CI) was calculated in bivariate and multivariate analyses. Statistically significant variables in the bivariate analyses were entered into the multivariate model. Multivariate ordinal logistic regression models were employed to examine the factors associated with perceived risk of STIs and HIV, while controlling for some of the socio-demographic factors.

The research protocol was reviewed and approved by the Ethical Review Board at the University of Health Sciences, Vientiane, Lao PDR. Participants were informed about confidentiality and verbal consent was obtained. Parental consent was also obtained for those less than 18 years of age.

\section{Results}

\section{Socio-demographic characteristics}

The characteristics of the sexually experienced respondents (245 boys and 238 girls) are displayed in Table 1. The mean age of respondents was $16.4+1.65$ years with a range of 14 to 19 years. Overwhelmingly the majority of respondents were from the Akha ethnic group (84.5\%) and only 15.5 per cent were non-Akha. Results on the educational status showed 22.2 per cent were illiterate, and 48.2 per cent had finished primary school. Females

Table 1 Socio demographic characteristic of sexually experienced respondents, by selected characteristics, ( $n=483)$

\begin{tabular}{|c|c|c|c|c|c|c|c|}
\hline & \multicolumn{2}{|c|}{$\begin{array}{c}\text { Male } \\
(n=245)\end{array}$} & \multicolumn{2}{|c|}{$\begin{array}{c}\text { Female } \\
(n=238)\end{array}$} & \multicolumn{2}{|c|}{$\begin{array}{c}\text { Total } \\
(n=483)\end{array}$} & \multirow[t]{2}{*}{$P$ value } \\
\hline & $\mathbf{N}$ & $\overline{\%}$ & $\mathbf{N}$ & $\overline{\%}$ & $\mathbf{N}$ & $\%$ & \\
\hline Age & & & & & & & $<0.001$ \\
\hline $14-15$ & 73 & 29.8 & 109 & 45.8 & 182 & 37.7 & \\
\hline $16-19$ & 172 & 70.2 & 129 & 54.2 & 301 & 62.3 & \\
\hline Mean (Sd) & & $\begin{array}{r}16.8 \\
(1.64)\end{array}$ & & $\begin{array}{r}15.9 \\
(1.55)\end{array}$ & & $\begin{array}{r}16.4 \\
(1.65)\end{array}$ & \\
\hline Ethnicity & & & & & & & $<0.001^{*}$ \\
\hline Lao & 52 & 21.2 & 4 & 1.7 & 56 & 11.6 & \\
\hline Khamu & 1 & 0.4 & 0 & 0.0 & 1 & 0.2 & \\
\hline Hmong \& Yao & 17 & 6.9 & 1 & 0.4 & 18 & 3.7 & \\
\hline Akha & 175 & 71.4 & 233 & 97.9 & 408 & 84.5 & \\
\hline Level of schooling complete & & & & & & & $<0.001^{*}$ \\
\hline Never go to school & 17 & 6.9 & 90 & 37.8 & 107 & 22.2 & \\
\hline Primary School & 119 & 48.6 & 114 & 47.9 & 233 & 48.2 & \\
\hline Secondary school & 81 & 33.1 & 28 & 11.8 & 109 & 22.6 & \\
\hline Upper secondary school & 27 & 11.0 & 4 & 1.7 & 31 & 6.4 & \\
\hline Technical & 0 & 0.0 & 1 & 0.4 & 1 & 0.2 & \\
\hline University & 1 & 0.4 & 0 & 0 & 1 & 0.2 & \\
\hline Current going to school & & & & & & & $<0.001$ \\
\hline No & 118 & 48.2 & 175 & 73.5 & 293 & 60.7 & \\
\hline Yes & 127 & 51.8 & 63 & 26.5 & 190 & 39.3 & \\
\hline Living arrangement & & & & & & & $0.124^{*}$ \\
\hline Family & 235 & 95.9 & 235 & 95.9 & 470 & 97.3 & \\
\hline Dormitory & 8 & 3.3 & 3 & 1.3 & 11 & 2.3 & \\
\hline Other & 2 & 0.8 & 0 & 0.0 & 2 & 0.4 & \\
\hline
\end{tabular}

Note: ${ }^{*}=$ Fisher's exact. 
reported lower education levels than males $(37.8 \%$ versus $6.9 \%, \mathrm{p}<.001)$. More than one third $(39.3 \%)$ of adolescents were currently attending school with more boys than girls currently in school $(51.8 \%$ versus $25.5 \%, \mathrm{p}<.001)$. Almost all participants were living with parents $(97.3 \%)$.

\section{Sexual risk behaviors}

Six per cent of respondents reported ever having had anal sex (Table 2). Slightly less than two thirds initiated their first sexual intercourse before age 15. Two thirds of the sexually experienced males reported two or more sexual partners during their lifetime with the mean $3.1+3.65$ while only twelve per cent of girls reported this cumulative number of partners. Forty two per cent reported not having used any contraceptives at all, 30.2 per cent reported using a condom, 20 per cent used other methods such as oral contraceptives or withdrawal method and 8 per cent reported that they used a combination of condoms and other methods.

Fifty seven per cent of respondents had been sexually active during the last six months prior to the interview. Of those reporting being sexually active in the past six months, 48.5 per cent reported not using a condom (49.5\% of sexually active boys and $46.4 \%$ of sexually active girls, $\mathrm{p}=0.642$ ). Among those who reported using a condom, 27.7 per cent indicated using a condom every time they had sex. There was no significant difference in this response between males and females (24.2\% versus $35.7 \%$, $\mathrm{p}=0.397$ ). Forty seven respondents (more boys than girls) reported having more than two partners during the last six months prior to the interview with gender difference (54.2\% of boys versus $30.6 \%$ of girls, $\mathrm{p}<.001)$.

Two thirds of girls reported having experiences of "Vagina Breakthrough" and one fifth had experience of "welcome guest". Nearly 95 per cent of girls initiated Vagina Breakthrough" at age younger than 15 years old and the mean age of Vagina Breakthrough" was $14.7 \pm 1.37$. For boys, nearly all of them (90.9\%) reported having experienced open foreskin. Sixty per cent of boys started open foreskin at age less than 15 and the mean age of open foreskin was $14.2 \pm 1.13$.

\section{Knowledge and source of STIs/HIV}

The mean score of knowledge on STIs was 3.4 out of 12 , suggesting poor knowledge. Almost all respondents were aware that sexual intercourse was the transmission route for STIs. One third were aware that symptoms such as abnormal vaginal discharge and pain during urination were possible indications of STIs. About 26.3 per cent knew about the symptoms of STIs such as abnormal vaginal discharge for women and 36.2 per cent reported about the pain during urination as the STI symptom. Few were aware of possible complications of untreated STIs or that women infected with STIs can be asymptomatic. There was a sex difference regarding knowledge about STIs as female participants had lower knowledge compared to male respondents $(60.2 \%$ versus $39.8 \%, \mathrm{p}<.001)$.

Respondents had also a low knowledge about HIV (mean $3.4 \pm 2.02$ out of 8 ). Misperceptions included a person will not get HIV if she or he is taking antibiotics (32.5\%) and washes genital parts after sex (79.4\%). About 40 per cent thought a person could be infected with HIV by sharing a glass of water with someone who was HIV positive. Less than three fifth $(55.3 \%)$ of them had low knowledge on HIV.

\section{Psychological construct of self-efficacy and peer sexual norms}

The mean score of self-efficacy was 30.5 out of possible score of 65 , indicating middle self-efficacy. Males had higher self-efficacy than females (31.6 versus 27.9). Girls had more self-efficacy in relation to being able to abstain than boys (18 versus 17.6), while boys had more selfefficacy in relation to condom use compared to girls (14.4 versus 11.8) (Table 3).

Most of respondents reported permissive peer sexual norms with a mean of 5.4 of 14 . Females had fewer peers with permissive sexual norms than male respondents $(5.1+2.93$ versus $5.7+3.09)$.

\section{Reported STIs symptoms}

Only 4.1 per cent respondents reported having STI symptoms during the six months preceding the interview (Data not shown). Among those respondents reported having had STI symptoms, the most common STI symptoms was painful/burning sensation when urinating (30\%), itching around the sex organ (30\%) and discharge (25\%). Males were more likely to report STI symptoms compared to female respondents $(6.9 \%$ versus $1.3 \%, \mathrm{p}=.002)$. Three per cent of respondents reported a history of symptoms or signs associated with an STI during the past year, but there was no gender difference in reporting having STIs symptoms STIs (4.5\% versus $1.3 \%, \mathrm{p}=.034$ ) (Table 2 ).

\section{Perception of risk of STIs and HIV}

A high percentage of respondents reported that they were very afraid of getting STIs (82.6\%) and HIV (85.7\%) while fewer reported that they were a little afraid $(12.4 \%$ and $11.6 \%$ ) of getting STI or HIV (Table 4).

Twelve per cent of respondents considered themselves to be at high risk for getting STIs and 13 per cent regarded themselves to be at medium risk. An additional 17.2 per cent of the participants considered themselves to have low risk while 57.6 per cent regarded themselves to have no risk at all. Similar pattern of perceived risk to HIV was found with 58.4 per cent considering themselves to be at no risk. There was a statistically significant sex difference 
Table 2 Sexual risk behaviors $(n=483)$

\begin{tabular}{|c|c|c|c|c|c|c|c|}
\hline \multirow[t]{3}{*}{ Variable } & \multirow{2}{*}{\multicolumn{2}{|c|}{$\begin{array}{c}\text { Male } \\
(n=245) \\
\begin{array}{c}\text { Mean }+ \\
\text { SD }\end{array}\end{array}$}} & \multirow{2}{*}{\multicolumn{2}{|c|}{$\begin{array}{c}\begin{array}{c}\text { Female } \\
(n=238)\end{array} \\
\text { Mean + SD }\end{array}$}} & \multirow{2}{*}{\multicolumn{2}{|c|}{$\begin{array}{c}\text { Total } \\
(\mathrm{N}=483) \\
\text { Mean + SD }\end{array}$}} & \multirow[t]{3}{*}{$P$ value } \\
\hline & & & & & & & \\
\hline & & & & & $\mathbf{N}$ & $\overline{\%}$ & \\
\hline Ever had oral sex & & & & & & & 0.011 \\
\hline No & 223 & 91.0 & 230 & 96.6 & 453 & 93.8 & \\
\hline Yes & 22 & 9.0 & 8 & 3.4 & 30 & 6.2 & \\
\hline
\end{tabular}

Ever had anal sex

0.088

$\begin{array}{rrrrrrr}\text { No } & 227 & 92.7 & 229 & 96.2 & 455 & 94.4 \\ \text { Yes } & 18 & 7.3 & 9 & 3.8 & 27 & 5.6\end{array}$

Experienced

"Open foreskin"

$(n=245)$

No

$\begin{array}{llllll}70 & 28.6 & \mathrm{Na} & \mathrm{Na} & 70 & 28.6\end{array}$

Yes

$\begin{array}{llllll}175 & 71.4 \quad \mathrm{Na} & \mathrm{Na} & 175 & 71.4\end{array}$

Experienced "Vagina breakthrough"

$(n=233)^{* *}$

No

Yes

Experienced

"Welcome guest"

$(n=233)^{* * *}$

No

Yes

Age at the first

time of sexual

intercourse

$(n=411)$

11-14 years old

$\begin{array}{llllll}118 & 48.2 & 185 & 77.7 & 303 & 62.7\end{array}$

15-18 years old

Mean \pm SD

Contraceptive

methods used at

the first sexual

intercourse

Condom only

Condom and

other method

Other method

only (OC)

Not method

$\begin{array}{rrrrrr}114 & 46.5 & 32 & 13.4 & 146 & 30.2 \\ 25 & 10.2 & 14 & 5.9 & 39 & 8.1 \\ 68 & 27.8 & 29 & 12.0 & 97 & 20.1 \\ 38 & 15.5 & 163 & 68.5 & 201 & 41.6 \\ \text { mean }+ & \text { mean }+ \text { sd } & \text { mean }+ \text { sd } \\ \text { sd }\end{array}$

Number of sexual partners during their lifetime

$$
\begin{array}{rrrrrr}
\mathrm{Na} & \mathrm{Na} & 5 & 2.2 & 5 & 2.2 \\
\mathrm{Na} & \mathrm{Na} & 228 & 97.8 & 228 & 97.8 \\
& & & & & \\
& & & & & \\
\mathrm{Na} & \mathrm{Na} & 163 & 68.5 & 163 & 68.5 \\
& & 73 & 31.5 & 73 & 31.5 \\
\text { mean + } \\
\text { sd }
\end{array}
$$$$
\begin{array}{rrrrrr}
118 & 48.2 & 185 & 77.7 & 303 & 62.7 \\
127 & 51.8 & 53 & 22.3 & 180 & 37.3 \\
14.6 & 1.46 & 1.12 & 13.7 & 1.38 & 14.2
\end{array}
$$$$
\begin{array}{rrrrrr}
118 & 48.2 & 185 & 77.7 & 303 & 62.7 \\
127 & 51.8 & 53 & 22.3 & 180 & 37.3 \\
14.6 & 1.46 & 1.12 & 13.7 & 1.38 & 14.2
\end{array}
$$$$
<0.001
$$$$
<\text { half of the occasions }
$$$$
\text { During half of the }
$$$$
\text { occasions }
$$

> half of the occasions

Always

Having STls symptoms

$<0.001$ during the last year

$$
\begin{aligned}
& \text { No } \\
& \text { Yes }
\end{aligned}
$$$$
\text { Note: }
$$$$
\text { ** = Five female respondents did not answer to questions "Vagina }
$$$$
\text { Breakthrough" and "Welcome Guest". }
$$

NA-is not applicable as Open foreskin is for boys; "Vagina breakthrough" and "Welcome Guest" are for girls.

of the perception of risk of STIs and HIV with more females reporting to have a high risk compared to males.

\section{Correlates of risk perception}

In bivariate analysis, level of education, knowledge about sexual transmission of STIs, peer sexual norms, early age at first sex, multiple sexual partners, and exposure to STI symptoms were significant related to adolescent's perception of personal risk of STIs (see Table 5). While 
Table 3 Score of the self-efficacy and peer sexual norm among sexually experienced respondents

\begin{tabular}{|c|c|c|c|}
\hline \multirow[t]{3}{*}{ Statement } & Total (483) & Male (245) & Female (238) \\
\hline & Mean (SD) & Mean (SD) & Mean (SD) \\
\hline & Min: $\max$ & Min: $\max$ & Min: $\max$ \\
\hline \multirow{2}{*}{$\begin{array}{l}\text { Self-Efficacy in } \\
\text { abstinence }\end{array}$} & $17.8(9.264)$ & $17.6(8.930)$ & $18.0(9.604)$ \\
\hline & $0: 40$ & 0: 39 & $0: 40$ \\
\hline \multirow{2}{*}{$\begin{array}{l}\text { Self efficacy in } \\
\text { condom use }\end{array}$} & 13.69 (6.533) & 14.4 (6.491) & $11.8(6.307)$ \\
\hline & $0: 28$ & $0: 28$ & $0: 27$ \\
\hline \multirow{2}{*}{$\begin{array}{l}\text { Self-efficacy in } \\
\text { partner } \\
\text { communication }\end{array}$} & $3.8(2.259)$ & $3.9(2.189)$ & 3.6 (2.409) \\
\hline & $0: 8$ & $0: 8$ & $0: 8$ \\
\hline \multirow{2}{*}{$\begin{array}{l}\text { Total mean score } \\
\text { self-efficacy }\end{array}$} & 30.5 (12.475) & $31.6(12.771)$ & 27.9 (11.438) \\
\hline & $0: 65$ & $0: 65$ & 5: 64 \\
\hline \multirow[t]{2}{*}{ Peer sexual norms } & $5.4(3.028)$ & $5.7(3.095)$ & $5.1(2.931)$ \\
\hline & $0 \& 14$ & $0 \& 13$ & $0 \& 14$ \\
\hline
\end{tabular}

Table 4 Perception of risk getting STIs and HIV among sexually experienced adolescents $(\mathrm{N}=483)$

\begin{tabular}{|c|c|c|c|c|c|c|c|}
\hline \multirow[t]{2}{*}{ Perception } & \multicolumn{2}{|c|}{$\begin{array}{c}\text { Male } \\
(n=245)\end{array}$} & \multicolumn{2}{|c|}{$\begin{array}{c}\text { Female } \\
(n=238)\end{array}$} & \multicolumn{2}{|c|}{$\begin{array}{c}\text { Total } \\
(n=483)\end{array}$} & \multirow[t]{2}{*}{$P$ value } \\
\hline & $\mathbf{N}$ & $\%$ & $n$ & $\%$ & $\mathbf{N}$ & $\%$ & \\
\hline Afraid of getting STIs & & & & & & & 0.362 \\
\hline Not afraid at all & 20 & 8.2 & 27 & 11.3 & 47 & 9.7 & \\
\hline Afraid a little & 8 & 3.3 & 5 & 2.1 & 13 & 2.7 & \\
\hline Afraid somewhat & 15 & 6.1 & 9 & 3.8 & 24 & 4.9 & \\
\hline Afraid a lot & 202 & 82.4 & 197 & 82.8 & 399 & 82.1 & \\
\hline
\end{tabular}

Perception of getting STIs

$\begin{array}{lrrrrrr}\text { No risk } & 154 & 62.9 & 124 & 52.1 & 278 & 57.2 \\ \text { Low risk } & 49 & 20.0 & 34 & 14.3 & 83 & 17.1 \\ \text { Medium risk } & 22 & 9.0 & 41 & 17.2 & 63 & 13 \\ \text { High risk } & 20 & 8.2 & 39 & 16.4 & 59 & 12.1\end{array}$

Afraid of getting HIV/AIDS

\begin{tabular}{lrrrrrrr} 
Afraid at all & 21 & 8.6 & 25 & 10.5 & 46 & 9.5 \\
Afraid a little & 4 & 1.6 & 6 & 2.5 & 10 & 2.1 & \\
Afraid somewhat & 5 & 2.0 & 8 & 3.4 & 13 & 2.7 & \\
Afraid a lot & 215 & 87.8 & 199 & 83.6 & 414 & 85.2 & \\
$\begin{array}{l}\text { Perception of getting } \\
\text { HIV/AIDS }\end{array}$ & & & & & & & 0.004 \\
No risk & 155 & 63.3 & 127 & 53.4 & 282 & 58.4 \\
Low risk & 46 & 18.8 & 35 & 14.7 & 81 & 16.8 \\
Medium risk & 24 & 9.8 & 37 & 15.5 & 61 & 12.6 \\
High risk & 20 & 8.2 & 39 & 16.4 & 59 & 12.2 \\
\hline
\end{tabular}

male sex, knowledge of STIs and HIV, peer sexual norms, early age at first sex, and multiple sex partners were significantly associated with perceived risk of HIV (Table 6).

After controlling for confounding variables, in multivariate logistic regression analysis, factors associated with perceived personal high risk of getting STIs were: being male $(\mathrm{OR}=0.5,95 \% \mathrm{CI}: 0.3-0.8, \mathrm{p} \leq .05)$, high level of knowledge about STIs $(\mathrm{OR}=1.3,95 \% \mathrm{CI}: 1.1-1.4, \mathrm{p} \leq .001)$; and having had symptoms of STIs in last six months $(\mathrm{OR}=$ 3.1, 95\% CI: 1.1-9.2, $\mathrm{p} \leq .05$ ) (Table 5). Perceived risk of getting HIV was significantly associated with being male $(\mathrm{OR}=0.5,95 \% \mathrm{CI}: 0.3-0.8, p \leq 0.01)$, having more knowledge about STIs (OR $=1.3,95 \% \mathrm{CI}: 1.2-1.5, p \leq .001)$, and knowledge about HIV (OR = 1.1, 95\% CI: 1.1-1.4, $p \leq .05)$ (Table 6).

\section{Discussion}

This study explores risk perceptions regarding STIs and HIV and associated factors across a wide spectrum of socio-demographic and socio-cultural context in Northern Lao PDR. Our results indicate that the individual and psychological factors are important in understanding risk perception of getting STIs and HIV.

\section{Risk perception of STIs/HIV}

The study revealed a tendency for adolescents, especially boys, to underreport their risk of contracting HIV. Slightly higher than two thirds of our respondents $(74.4 \%$ and $75.2 \%$ ) perceived themselves as to be at no or low risk of STIs and HIV infection respectively even though they reported that they had unprotected sex, which could result in STIs/HIV infection. This could be a reflection of their low level of knowledge about STIs and HIV and the low knowledge of what should be considered risk factors for STI and HIV. Similarly, previous study carried out in Luangnamtha province revealed an alarming lack of HIV/ AIDS knowledge [47]. Misconceptions and erroneous views about HIV transmission may influence decisions and also make the person interpret the actual odds of getting an infection wrongly [48,49], which vary across cultural context. The other reason could be that the participants did not know how to assess their risk and they might not be able to apply their knowledge of disease transmission to assess their risk level every time they engage in sexual activity. Furthermore fewer girls than boys reported that they were at risk compared to boys. These findings highlight the gap between the level of risk perception versus the actual sexual risk behaviors and also show a lack of understanding regarding the consequences of risky sexual behaviors. These findings were consistent with previous studies carried out in elsewhere [50,51], but there was no data on the risk perception to HIV/AIDS in Lao PDR to compare. 
Table 5 Bivariate and multivariate ordinal analyses of factor associated with risk perceptions of getting STls among sexually experienced adolescents in LNT province $(N=483)$

\begin{tabular}{|c|c|c|c|c|c|c|c|c|}
\hline \multirow[t]{2}{*}{ Factors } & \multirow[t]{2}{*}{ No risk \% } & \multirow[t]{2}{*}{ Low risk \% } & \multirow[t]{2}{*}{ Medium risk \% } & \multirow[t]{2}{*}{ High risk \% } & \multicolumn{2}{|c|}{ Crude } & \multicolumn{2}{|c|}{ Adjusted } \\
\hline & & & & & OR & $95 \% \mathrm{Cl}$ & OR & $95 \% \mathrm{Cl}$ \\
\hline \multicolumn{9}{|l|}{$\operatorname{Sex}(n=483)$} \\
\hline Female & 52.1 & 14.3 & 17.2 & 16.4 & 1 & & 1 & \\
\hline Male & 62.9 & 20.0 & 9.0 & 8.1 & $0.6^{* *}$ & $0.4-0.8$ & $0.5^{*}$ & $0.3-0.8$ \\
\hline \multicolumn{9}{|l|}{ Age } \\
\hline $14-15$ yrs & 55.0 & 17.0 & 12.6 & 15.4 & 1 & & 1 & \\
\hline $16-19$ yrs & 59.1 & 17.3 & 13.3 & 10.3 & 0.8 & $0.6-1.1$ & 0.8 & $0.5-1.2$ \\
\hline \multicolumn{9}{|l|}{ Ethnicity } \\
\hline Non-Akha & 52.0 & 25.3 & 13.3 & 9.4 & 1 & & 1 & \\
\hline Akha & 58.6 & 15.7 & 13.0 & 12.7 & 0.9 & $0.6-1.4$ & 0.5 & $0.3-0.9$ \\
\hline \multicolumn{9}{|l|}{ Level of education } \\
\hline Never go to school & 52.3 & 15.0 & 15.9 & 16.8 & 1 & & 1 & \\
\hline Primary school & 57.5 & 17.6 & 11.2 & 13.7 & 0.8 & $0.5-1.2$ & 0.8 & $0.5-1.4$ \\
\hline Secondary school \& higher & 61.5 & 18.2 & 14.0 & 6.3 & $0.6^{*}$ & $0.4-0.98$ & 0.7 & $0.4-1.2$ \\
\hline Living arrangement & & & & & & & NA & \\
\hline Family & 57.0 & 17.2 & 13.4 & 12.4 & 1 & & & \\
\hline Others & 76.9 & 15.4 & 0 & 7.7 & 0.4 & $0.1-1.4$ & & \\
\hline \multicolumn{9}{|l|}{ Knowledge on STIs } \\
\hline Mean (SD) & $3.0(1.44)$ & $3.8(1.91)$ & $4.4(1.77)$ & $3.5(1.26)$ & & & & \\
\hline Min: Max & $0: 9$ & $0: 9$ & 1: 10 & $1: 6$ & $1.3^{* * *}$ & $1.2-1.5$ & $1.3^{* * *}$ & $1.1-1.4$ \\
\hline \multicolumn{9}{|l|}{ Knowledge on HIV/AIDS } \\
\hline Mean (SD) & $3.2(1.91)$ & $4.4(2.17)$ & $3.6(1.95)$ & $2.8(1.60)$ & & & & \\
\hline Min: Max & $0: 8$ & $0: 8$ & $0: 8$ & $0: 8$ & 1.1 & $0.97-1.2$ & NA & \\
\hline \multicolumn{9}{|l|}{ Self-efficacy } \\
\hline Mean (SD) & $29.3(12.67)$ & $33.2(12.08)$ & $31.6(10.21)$ & $30.2(14.04)$ & & & & \\
\hline Min: Max & $0: 65$ & 8: 64 & 11: 55 & 4: 50 & 1.01 & $0.99-1.03$ & NA & \\
\hline \multicolumn{9}{|l|}{ Peer sexual norms } \\
\hline Mean (SD) & $5.6(3.14)$ & $5.7(2.78)$ & $4.4(2.70)$ & $5.0(2.93)$ & & & & \\
\hline Min: Max & $0: 14$ & $0: 12$ & $0: 12$ & $0: 12$ & $0.9^{*}$ & $0.87-0.98$ & 0.9 & $0.9-1.1$ \\
\hline \multicolumn{9}{|l|}{ Early age at first sex } \\
\hline$<15$ years & 54.1 & 17.5 & 13.5 & 14.9 & 1 & & 1 & \\
\hline$>15$ years & 63.3 & 16.7 & 12.2 & 7.8 & $0.7^{*}$ & $0.5-0.9$ & 0.9 & $0.6-1.3$ \\
\hline \multicolumn{9}{|l|}{ Multiple sex partners } \\
\hline 1 person & 51.1 & 15.1 & 16.1 & 17.7 & 1 & & 1 & \\
\hline$>=2$ persons & 61.6 & 18.5 & 11.1 & 8.8 & $0.6^{*}$ & $0.4-0.8$ & 0.8 & $0.5-1.3$ \\
\hline Custom sexual practice & & & & & & & NA & \\
\hline No & 50.0 & 25.0 & 16.3 & 8.7 & 1 & & & \\
\hline Yes & 59.1 & 15.6 & 12.4 & 12.9 & 0.8 & $0.5-1.3$ & & \\
\hline Anal sex & & & & & & & NA & \\
\hline No & 57.7 & 17.3 & 12.9 & 12.1 & 1 & & & \\
\hline Yes & 55.6 & 14.8 & 14.8 & 14.8 & 1.1 & $0.5-2.4$ & & \\
\hline
\end{tabular}


Table 5 Bivariate and multivariate ordinal analyses of factor associated with risk perceptions of getting STls among sexually experienced adolescents in LNT province $(\mathrm{N}=483)$ (Continued)

\begin{tabular}{|c|c|c|c|c|c|c|c|c|}
\hline \multicolumn{9}{|c|}{ Condom use during the last 6 months } \\
\hline No & 60.3 & 22.0 & 9.2 & 8.5 & 1 & \multicolumn{3}{|c|}{ NA } \\
\hline Yes & 55.6 & 19.6 & 13.5 & 11.3 & 1.3 & $0.8-2.0$ & & \\
\hline \multicolumn{9}{|c|}{ Having STIs symptoms } \\
\hline No & 58.3 & 17.3 & 13.4 & $11 / 0$ & 1 & & 1 & \\
\hline Yes & 40.0 & 15.0 & 5.0 & 40.0 & $3.0^{*}$ & $1.2-7.2$ & $3.1^{*}$ & $1.1-9.2$ \\
\hline
\end{tabular}

${ }^{*} \mathrm{P}<0.05$.

**P $<0.005$.

***P $<0.001$.

\section{Predictors of perceived risk getting of STIs/HIV}

Existing literature show mixed results on the association between risk perception and sexual behavior. Our findings suggest that perception of the risk of getting STIs/ HIV among adolescents in Luangnamtha province was related to a number of factors operating at the individual level. Demographic factors that influence risk perception are sex, knowledge about STIs and HIV, and peer sexual norms also being strongly correlated with the risk judgments of individual perception regarding risk.

The influence of gender has been well documented, with boys tending to judge risks as smaller as and less problematic than girls [52-54]. Explanations have focused mainly on biological and social factors. For example, it has been suggested that girls are more socialized to care for human health and are less likely to be familiar with science and technology [55]. Other issues relate to power imbalance and social control [56]. In Lao PDR for example, men typically feel more empowered to express their sexual desires and sexually risky behaviour among male is generally more acceptable $[9,47]$. This could be also explained that women and men often express different levels of concern about the same risks; they perceive different risks and different meaning attributed to the same risks [51].

The study found no association between the traditional sexual customs and perceived risks of STIs/HIV, which was similar to previous studies [19]. The explanation could be that the traditional sexual practices may not necessarily lead to increased perception of HIV risk if these practices are socially supported by the community and families [10]. For Akha adolescents for example, the perceived risk of STIs/HIV is likely to be interpreted within their cultural beliefs in which practices such as Breakthrough Vagina are an essential and normal part of transitioning into a mature adult [9].

\section{Knowledge about STIs and HIV}

The association between perceiving oneself to be at high risk and having knowledge about STIs/HIV is plausible. Respondents who had high knowledge about STIs/HIV might have felt more at risk because they knew that they might get infected. Those unaware of this on the other hand, might believe that only those looking sick, in practice terminally ill persons, might pose a risk for transmission, which is a false and potentially dangerous perception. They might apply their knowledge of disease transmission to assess their risk level every time they engage in sexual activity. This is supported by the fact that women had less knowledge and also fewer women report that they were at risk. Our study was similar to previous studies [51,57] which suggested a positive association between risk perception of STIs/HIV and knowledge about STIs/HIV. The HBM considers knowledge about AIDS as essential for sexual behavior change. For instance, some researchers Zellner [58] described knowledge about AIDS as a form of self-empowerment that may influence a person's perception of risk and create awareness and thus stimulate behaviour change [58]. On the other hand, some researchers have found that having more knowledge about HIV did not correlate significantly with risk perception for HIV [59]. However, there are no previous studies related to risk perceptions have been carried out in the Lao PDR, highlighting the need to have valid and comparable data.

In our study, risk perception related to STIs and HIV was not associated with number of sex partners during lifetime, condom use and age at first sex. The reason could be that the participants did not perceive themselves at risk or they did not perceive themselves at risk because they have stable sexual relationships or they were not aware of their partner's sexual practice. The lack of significant association between condom use and perceived risk of getting STIs and HIV might reflect the low preference for condom use relative to other methods such as abstinence. On the other hand, other studies from sub-Saharan Africa have found a positive association between perceived risk and risky sexual behaviour for both women and men $[19,60]$. Some researchers found a negative association between perceived risks of HIV with sexual behaviours [22,23]. Further the cultural acceptability of multiple partners, particularly for males [9], may moderate young people's perception of risk. 
Table 6 Bivariate and multivariate analyses of factor associated with risk perceptions of getting HIV among sexually experienced adolescents in LNT province

\begin{tabular}{|c|c|c|c|c|c|c|c|c|}
\hline \multirow[t]{2}{*}{ Factors } & \multirow[t]{2}{*}{ No risk \% } & \multirow[t]{2}{*}{ Low risk \% } & \multirow[t]{2}{*}{ Medium risk \% } & \multirow[t]{2}{*}{ High risk \% } & \multicolumn{2}{|c|}{ Crude } & \multicolumn{2}{|c|}{ Adjusted } \\
\hline & & & & & OR & $95 \% \mathrm{Cl}$ & OR & $95 \% \mathrm{Cl}$ \\
\hline \multicolumn{9}{|l|}{ Sex } \\
\hline Female & 53.4 & 14.7 & 15.5 & 16.4 & 1 & & 1 & \\
\hline Male & 63.3 & 18.8 & 9.8 & 8.2 & $0.6^{* *}$ & $0.4-0.8$ & $0.5^{* *}$ & $0.3-0.8$ \\
\hline \multicolumn{9}{|l|}{ Age } \\
\hline $14-15$ yrs & 53.3 & 18.1 & 13.7 & 14.8 & 1 & & 1 & \\
\hline $16-19$ yrs & 61.5 & 15.9 & 12.0 & 10.6 & 0.7 & $0.5-1.01$ & 0.7 & $0.5-1.2$ \\
\hline \multicolumn{9}{|l|}{ Ethnicity } \\
\hline Non-Akha & 53.3 & 22.7 & 14.7 & 9.3 & 1 & & 1 & \\
\hline Akha & 59.3 & 15.7 & 12.3 & 12.7 & 0.9 & $0.6-1.4$ & 0.6 & $0.3-1.1$ \\
\hline \multicolumn{9}{|l|}{ Level of education } \\
\hline Never go to school & 53.3 & 17.7 & 10.3 & 18.7 & 1 & & 1 & \\
\hline Primary school & 59.6 & 16.3 & 12.9 & 11.2 & 0.7 & $0.5-1.1$ & 0.8 & $0.5-1.3$ \\
\hline Secondary school \& higher & 60.1 & 16.8 & 14.0 & 9.1 & 0.7 & $0.4-1.1$ & 0.7 & $0.4-1.3$ \\
\hline \multicolumn{9}{|l|}{ Living arrangement } \\
\hline Family & 58.5 & 16.6 & 12.6 & 12.3 & 1 & & NA & \\
\hline Others & 53.8 & 23.1 & 15.4 & 7.7 & 1.1 & $0.4-2.9$ & & \\
\hline \multicolumn{9}{|l|}{ Knowledge on STIs } \\
\hline Mean (SD) & $3.0(1.40)$ & $4.0(1.94)$ & $4.0(1.85)$ & $3.7(1.40)$ & & & & \\
\hline Min: Max & 0: 9 & 1:9 9 & $0: 10$ & $1: 7$ & $1.3^{* * *}$ & $1.2-1.5$ & $1.3^{* * *}$ & $1.2-1.5$ \\
\hline \multicolumn{9}{|l|}{ Knowledge on HIV /AIDS } \\
\hline Mean (SD) & $3.2(1.96)$ & $4.3(2.13)$ & $3.6(1.68)$ & $3.1(1.86)$ & & & & \\
\hline Min: Max & $0: 8$ & $0: 8$ & $0: 8$ & $0: 8$ & $1.1^{*}$ & $1.0-1.2$ & $1.1^{*}$ & $1.1-1.4$ \\
\hline \multicolumn{9}{|l|}{ Self-efficacy } \\
\hline Mean (SD) & $29.1(12.95)$ & $33.9(11.27)$ & $31.4(10.94)$ & $31.2(12.48)$ & & & & \\
\hline Min: Max & $0: 65$ & 8: 64 & 10: 56 & 450 & 1.01 & $0.99-1.03$ & NA & \\
\hline \multicolumn{9}{|l|}{ Peer sexual norms } \\
\hline Mean (SD) & $5.7(3.12)$ & $5.0(2.75)$ & $4.6(2.78)$ & 5.2 & & & & \\
\hline Min: Max & $0: 14$ & $0: 13$ & $0: 12$ & (2.99) 0: 12 & $0.9^{*}$ & $0.86-0.97$ & 0.95 & $0.89-1.02$ \\
\hline \multicolumn{9}{|l|}{ Early age at first sex } \\
\hline$<15$ years & 54.5 & 17.8 & 11.9 & 15.8 & 1 & & 1 & \\
\hline$>15$ years & 65.0 & 15.0 & 13.9 & 6.1 & $0.6^{*}$ & $0.4-0.9$ & 0.9 & $0.6-1.5$ \\
\hline \multicolumn{9}{|l|}{ Multiple sex partners } \\
\hline 1 person & 52.1 & 16.1 & 16.7 & 15.1 & 1 & & 1 & \\
\hline$>=2$ persons & 62.3 & 17.2 & 10.1 & 10.4 & $0.6^{*}$ & $0.4-0.9$ & 0.95 & $0.6-1.5$ \\
\hline \multicolumn{9}{|l|}{ Custom sexual practice } \\
\hline No & 53.8 & 21.2 & 16.2 & 8.8 & 1 & & NA & \\
\hline Yes & 59.3 & 15.9 & 11.9 & 12.9 & 0.9 & $0.6-1.4$ & & \\
\hline \multicolumn{9}{|l|}{ Anal sex } \\
\hline No & 57.7 & 16.9 & 12.9 & 12.5 & 1 & & NA & \\
\hline Yes & 70.4 & 14.8 & 7.4 & 7.4 & 0.6 & $0.2-1.3$ & & \\
\hline
\end{tabular}


Table 6 Bivariate and multivariate analyses of factor associated with risk perceptions of getting HIV among sexually experienced adolescents in LNT province (Continued)

\begin{tabular}{|c|c|c|c|c|c|c|c|}
\hline \multicolumn{8}{|c|}{ Condom use during the last 6 months } \\
\hline No & 59.6 & 21.3 & 7.8 & 11.3 & 1 & & NA \\
\hline Yes & 57.1 & 13.5 & 14.3 & 15.1 & 1.2 & $0.8-2.0$ & \\
\hline Having STIs symptoms & & & & & & & NA \\
\hline No & 58.5 & 16.9 & 12.7 & 11.9 & 1 & & \\
\hline Yes & 55.0 & 15.0 & 10.0 & 20.0 & 1.3 & $0.5-3.0$ & \\
\hline
\end{tabular}

${ }^{*} \mathrm{P}<0.05$.

**P $<0.005$.

***P $<0.001$

\section{Reported STIs symptoms}

Having STIs symptoms reinforce adolescent's STIs and HIV/AIDS risk perception [18]. Our study found a positive association between reporting having symptoms of STIs and perceived risk of getting STIs/HIV, which is similar to previous studies [61]. This could be explained by the fact that those who had STIs had become aware that they were not immune to diseases, including HIV/AIDS. It could also be an effect of the STI/HIV educational campaign program from the Ministry of Health, Lao PDR. Having an STI symptom might lead adolescents to get to know prevention measure of STIs and HIV. This knowledge facilitates adolescent's awareness and might assist them to identify risky situations. However, some researchers found no association between reporting of STIs and perceived of risk getting STIs [62,63]. In Lao PDR, to date there are no studies on the relationship of reported STIs symptoms and risk perception of STIs/HIV to compare.

\section{Limitation}

This study must acknowledge some limitations. Foremost, any generalization from the results of this study should be made with caution. Because of the cross-sectional nature of our data we are not able to draw conclusions about causal effect. Additional studies using a prospective cohort design will be necessary to evaluate the significance and stability of these predictors to influence perceived risk of getting STIs/HIV/AIDS. Secondly, we over sampled Akha ethnicity aged 14-19 years old, which is due to concentration of the ethnic group Akha in the Long and Sing districts and high proportion of sexually active Akha adolescents compared to adolescents from other ethnic groups. The level of risk in this sample is likely to be higher than among adolescents from other ethnic groups due to traditional sexual customs. This may limit the reliability of the findings, especially as they relate to ethnic differences. Thirdly, we need to acknowledge the difficulties in measuring knowledge and other psychological constructs, which did not demonstrate strong psychometric properties in our sample, probably because of the low literacy level. This indicates a need to refine these measures and be cautious when interpreting the findings. The measurement of risk perceptions by using a single item is not reliable compared to scale construct. However, many previous studies have used single-item variables rather than scales $[64,65]$. The sensitive nature of sexual behaviors such as sexual practice, number of sexual partners, condom use, and past STIs might have been underreported because of social desirability bias. A number of steps however were undertaken to minimize this, including use of trained interviewers, gender matching between interviewers and participants, and ensuring confidential interview settings. Despite these limitations the study contributes to an understanding of the risk perceptions of an under-researched population in relation to their vulnerabilities to STIs/HIV infection. The findings are useful for informing interventions that aim to increase young people's ability to accurately gauge their risks relative to their sexual behaviour. More qualitative research will provide further understanding of the link between risk perceptions, risk taking and factor shaping perceived risk of getting STIs and HIV/AIDS among young people require that attention is paid to the dynamics of sexual relationship, the individual characteristics, and the structural environmental factors that facilitate preventive behaviors.

\section{Conclusion}

This study investigated the risk perceptions and factors associated with the risk perception of getting STIs/HIV among adolescents in one rural area of Lao PDR. Sociodemographic factors, knowledge of STIs/HIV, and the level of exposure to STIs were the main determinants of the risk perception of STIs/HIV.

These findings highlight a need for programmes that can create greater awareness of the risk of STIs/HIV among young adolescents in the Northern part of Lao PDR. Young people should be at the center of strategies to control HIV infection and addressing inaccurate perception of risk may be a key to improve safer sexual practices. The risk of STIs and HIV/AIDS infection is higher for unprotected anal sex compared with unprotected vaginal and oral sexual intercourse. Tailored messages are therefore needed to address adolescent risk perceptions related 
to anal sex as well as other forms of sexual intercourse. This study also underscores the complexity of the relationship between risk perception and sexual risk behaviors and traditional cultural practices thus the need to study the relationships between sexual risk behaviors and perception of risk behaviors more in depth. More qualitative research is needed to explore the structural and environmental circumstances that characterize risk perception and sexual relations, the social dimension of risk, the reasons of risk, and the life skills needed in order to negotiate risk reduction.

\section{Additional file}

Additional file 1: Risk perceptions of STIs/HIV and sexual risk behaviours among sexually experienced adolescents in the Northern part of Lao PDR.

\section{Competing interests}

The authors declare that they have no competing interests.

\section{Authors' contributions}

SV developed the research proposal, designed the instrument, and collected data in the field sites, analyzed and wrote the draft manuscript. EF contributed to the development of research design, analyzing and finalized the manuscript. KC assisted in the survey instrument development, data collection, data analysis and also contributed to the final version of the manuscript. ST contributed to the analysis and writing manuscript. All authors read and approved the final manuscript.

\section{Acknowledgements}

This study was supported by Sida. The authors would like to express their gratitude to the Luangnamtha Provincial Department, Long and Sing district health offices for their assistance in communication and approval for field data collection, as well as to the many adolescents who kindly gave of their time to participate in this study. We also would like to express our gratitude thank to the data collection team from the Faculty of Postgraduate Studies, University of Health Sciences.

\section{Author details}

${ }^{1}$ Faculty of Postgraduate Studies, University of Health Sciences, Samsenthia Road, P.O.Box 7444, Vientiane, Lao PDR. ${ }^{2}$ Division of Global Health (IHCAR), Department of Public Health Sciences, Karolinska Institutet, SE 17177 Stockholm, Sweden. ${ }^{3}$ Faculty of Basic Sciences, University of Health Sciences, Samsenthia Road, P.O.Box 7444, Vientiane, Lao PDR.

Received: 18 February 2013 Accepted: 26 November 2013 Published: 5 December 2013

\section{References}

1. UNAIDS, UNICEF, WHO: Epidemiological fact sheet on HIV/AIDS and sexually transmitted infectious: 2004 update. Geneva: UNAIDS/WHO Working Group on Global HIV/AIDS and STI Surveillance; 2004.

2. Center for control HIV/AIDS and STIs, Ministry of Health: Annual report of CHAS. Vientiane, Lao PDR; 2011.

3. Fleming DT, Wasserheit JN: From epidemiological synergy to public health-policy and practice: the contribution of other sexually transmitted diseases to sexual transmission of HIV infection. Sex Transm Inf 1999, 75:3-17.

4. WHO: HIV/AIDS in the South-East Asia Region: Report of the15th Meeting of the National AIDS Programme Managers. Kathmandu, Nepal; 2000. http:// whqlibdoc.who.int/searo/2001/SEA_AIDS_121.pdf.

5. Chamberlain J: HIV Vulnerability and Population Mobility in the Northern Provinces of the Lao PDR, The HIV/AIDS Trust, Lao PDR, The National Committee for the Control of AIDS, and UNDP Vientiane. 2003:1-46.
6. CHAS: National Strategic Prevention of HIV/AIDS/STIs-2011-2015. Lao People's Democratic Republic: Ministry of Health; 2011.

7. Harrison A, Xaba N, Kunene P, Ntuli N: Understanding young women's risk for HIV/AIDS: adolescent sexuality and vulnerability in rural KwaZulu Natal. Soc Transit 2001, 32(1):69-77.

8. Sales JM, DiClemente RJ: Adolescent STI/HIV prevention programs: what works for teens? ACT for Youth Center of excellence: research Facts and Findings. A collaboration of Cornell University, University of Rochester, and New York State Center for School Safety; 2010. http://www.actforyouth.net/resources/ rf/rf_sti_0510.pdf.

9. Sychareun V, Faxelid E, Thomsen S, Somphet V, Popenoe R: Customary adolescent sexual practices among the Akha of northern Lao PDR: considerations for public health. Cult Health Sex 2011, 14:1-14.

10. Auerbach J: Transforming social structures and environments to help in HIV prevention. Health Aff 2009, 28(6):1655-1665.

11. Blankenship KM, Friedman SR, Dworkin S, Mantell JE: Structural interventions: concepts, challenges, and opportunities for research. J Urban Health 2006, 83(1):59-72.

12. Tomlinson RH, Rohleder P, Swartz L, Drimie S, Kagee A: Broadening psychology's contribution to addressing issues of HIV/AIDS, poverty and nutrition: structural issues as constraints and opportunities. J Health Psychol 2010, 15(7):972-981.

13. Gage AJ: Sexual activity and contraceptive use: the components of the decision making process. Stud Fam Plann 1998, 29(2):154-166.

14. Gubhaju B: Adolescent reproductive health in Asia. Bangkok, Thailand: Paper presented at the 2002 IUSSP Regional Population Conference "South-East Asia's Population in a Changing Asian Context"; 2012.

15. UNESCAP: Health without borders, Situational analysis-LAO PDR: national profile. 2005. www.unescap.org/esid/hds/pubs/2442/5_LaoPDR.pdf.

16. Magnani RJ, Karim AM, Weiss LA, Bond KC, Lemba M, Morgan GT: Reproductive health risk and protective factors among youth in Lusaka, Zambia. J Adolesc Health 2002, 30(1):76-86.

17. Dixon-Mueller: The sexuality connection in reproductive health. In Learning About Sexuality: A Practical Beginning. Edited by Zeidenstein S, Moore K. New York: Population Council and International Women's Health Coalition; 1996:137-157.

18. Bryan AD, Aiken LS, West SG: Young women's condom use: the influence of acceptance of sexuality, control over the sexual encounter, and perceived susceptibility to common STDs. Health Psychol 1997, 16:468-479.

19. Akwara PA, Madise NJ, Hinde A: Perception of risk of HIV/AIDS and sexual behaviour in Kenya. J Biosoc Sci 2003, 35(3):385-411.

20. Rosenstock IM: Historical origins of the health belief model. Health Educ Monogr 1974, 2:328-335.

21. Maticka-Tyndale T: Factors influencing the timing of first sexual intercourse among young people in Nyanza, Kenya. Int Fam Plann Perspect 2008, 34(4):177-188.

22. Anderson B, Maughan B: HIV risk perceptions and first sexual intercourse among youth in Cape Town, South Africa. Int Fam Plann Perspect 2007, 33(3):98-105.

23. Tenkorang E, Rajulton F, Maticka-Tyndale E: Perceived risks of HIV/AIDS and first sexual intercourse among youth in Cape Town, South Africa. AIDS Behav 2009, 13(2):234-245.

24. Toroitich-Ruto C: The determinants of teenage sexuality and their understanding of STD/HIV/AIDS in Kenya. Afr Popul Stud 1997, 12(2):39-50.

25. Anderson KG, Beutel AM, Maughan-Brown B: HIV/AIDS risk perceptions and first sexual intercourse among youth in Cape Town, South Africa. Centre Soc Sci Res: AIDS Soc Res Unit 2007(196 of CSSR Working paper):1-22. Centre for Social Science Research. AIDS and society research unit.

26. Fishbein M: The role of theory in HIV prevention. AIDS Care 2000, 12:273-278.

27. Bandura A: Social cognitive theory and exercise of control over HIV infection. In Preventing AIDS: theories and methods of behavioral interventions. Edited by DiClementee RJ, Peterson JL. New York: Plenum Press; 1994.

28. Fishbein $M$, Cappella J: The role of theory in developing effective health communications. J Commun 2006, 56(Supplement):S1-S7.

29. Thato S, Charron-Prochownik D, Dorn LD, Albrecht SA, Stone CA: Predictors of condom use among adolescent Thai vocational students. J Nurs Scholarsh 2003, 32(2):157-163.

30. Sieving E, McNeely S, Blum W: Maternal expectations, mother-child connectedness \& adolescent sexual debut. Arch Pediatr Adolesc Med 2003, 154:809-816. 
31. Potard C, Courtois R, Rusch E: The influence of peers on risky sexual behaviour during adolescence. Eur J Contracept Reprod Health Care 2008, 13(3):264-270

32. Kinsman SB, Romer D, Furstenberg FF, Schwarz DF: Early sexual initiation: the role of peer norms. Obstet Gynecol Survey 1999, 54(4):233-234.

33. Hollander D: Perceptions of peer behavior predict whether Peruvian adolescents have had sex. Fam Plann Perspect 2001, 27(3):154-161.

34. Luangnamtha Provincial Health Department: Annual statistical report 2011. Luangnamtha Province, Lao PDR; 2011.

35. Luangnamtha Provincial Education Department: Annual statistical report 2011. Luangnamtha Province, Lao PDR; 2011.

36. King E, van de Walle D: Schooling and poverty in Lao PDR 2005. Washington, DC: The World Bank, Development Research Group; 2005:1-90. Report No.: 39318-LA.

37. National Statistical Centre, Swiss National Centre of Competence in Research North-south, Centre Development and Environment, and Lao National Mekong Committee: Socio-economic ATLAS of the Lao PDR: an analysis based on the 2005 population and housing census. Vientiane; 2008.

38. UNESCO, UNAIDS: Handbook appropriate communication for behavior change: Information/Education/Communication: A cultural approach to HIVI AIDS Prevention and Care. 2001. http://unesdoc.unesco.org/images/0012/ 001255/125589e.pdf.

39. Bartlett JE, Kotrlik JW, Higgins CC: Organizational research: determining appropriate sample size in survey research. Inf Technol, Learn, Perform J 2001, 19(1):43-50.

40. World Health Organization: Maternal, newborn, child and adolescent health Geneva; 2013. Available at website<www.who.int/ maternal_child_adolescent/topics/adolescence/dev/en.

41. Sychareun V, Thomsen S, Faxelid E: Concurrent multiple health risk behaviors among adolescents in Luangnamtha province, Lao PDR. BMC Public Health 2011, 13:11-36.

42. Carey MP, Schroder KE: Development and psychometric evaluation of the brief HIV knowledge questionnaire. AIDS Educ Prev 2002, 14:172-182. PubMed: 12000234.

43. Volpe EM, Nelson LE, Kraus RA, Morrison-Beedy D: Adaptation and refinement of the HIV knowledge questionnaire for use with adolescent girls. J AssoC Nurses AIDS Care 2007, 18(5):57-63.

44. Thato S, Hanna K, Rodcumdee B: Translation and validation of the condom self-efficacy scale with Thai adolescents and young adults. J Nurs Scholarsh 2005, 37:36-40.

45. Shafer MA, Boyer CB: Psychosocial and behavioral factors associated with risk of sexually transmitted diseases, including human immunodeficiency virus infection, among urban high school students. J Pediatr 1991, 119:826-833.

46. La Greca AM, Prinstein MJ, Fetter MD: Adolescent peer crowd affiliation: linkages with health-risk behaviors and close friendships. J Pediatr Psychol 2001, 26:131-143.

47. Slesak G, Inthalad S, Kim J, et al: High HIV vulnerability of ethnic minorities after a trans-Asian highway construction in remote northern Laos. Int J STD AIDS 2012, 23:570-575. doi: 10.1258/ijsa.2012.011416.

48. BruinedeBruin W, Downs JS, Fischhoff B: Adolescents' thinking about the risks of sexual behaviors. In Thinking with data. Edited by Lovett M, Shah P. Mahwah, NJ: Erlbaum; 2007.

49. Bogart L, Thorburn S: Are HIV/AIDS conspiracy beliefs a barrier to HIV prevention among African Americans? AIDS J Acquir Immune Defic Syndr 2005, 38:213-218.

50. Adedimeji AA, Omololu FO, Odutolu O: HIV risk perception and constraints to protective behaviour among young slum dwellers in Ibadan, Nigeria. J of Health, Popu \& Nutri 2007, 25(2):146-157.

51. Prata N, Morris L, Mazive E, Vahidnia F, Stehr M: Relationship between HIV risk perception and condom use: evidence from a population-based survey in Mozambique. Int Fam Plann Perspect 2006, 32(4):192-200.

52. Gustafson PE: Gender differences in risk perception: theoretical and methodological perspectives. Risk Anal 1998, 18(6):805-811.

53. Holtzman D, Bland SD, Lansky A, Mack K: HIV-related behaviors and perceptions among adults in 25 states: 1997 behavioral risk factor surveillance system. Am J Public Health 2001, 91(11):1882-1888.

54. Ward EG, Disch WB, Levy JA, Schensul JJ: Perception of HIV/AIDS risk among urban, low-income Senior-housing residents. AIDS Educ Prev 2004, 16(6):571-588.
55. Anthony l: Akubue: gender disparity in third world technological, social, and economic development. J Technol 2001, 27:64-73.

56. Flynn J, Slovic P, Mertz CK: Gender, race and perception of environmental health risks. Risk Anal 1994, 14:1101-1108.

57. Maswanya ES, Moji K, Horiguchi I, Nagata K, Aoyagi K, Honda S, Takemoto T: Knowledge, risk perception of AIDS and reported sexual behaviour among students in secondary schools and colleges in Tanzania. Health Educ Res 1999, 14(2):185-196.

58. Zellner SL: Condom use and the accuracy of AIDS knowledge in Côte d'Ivoire. Int Fam Plann Perspect 2003, 29(1):41-47.

59. Stringer EM, Sinkala M, Kumwenda R, Chapman W, Mwale A, Vermund SH, Goldenberg RL, Stringer SA: Personal risk perception, HIV knowledge and risk avoidance behavior, and their relationships to actual HIV serostatus in an urban African obstetric population. J Acquir Immune Defic Syndr 2004, 35(1):60-66.

60. Macintyre K, Rutenberg N, Brown L, Karim A: Understanding perceptions of HIV risk among adolescents in KwaZulu-Natal. AIDS and Behav 2004, 8(3):237-250.

61. DiClemente RJ, Crittenden CP, Rose E, Sales JM, Wingood GM, Crosby RA, Salazar LF: Psychosocial predictors of HIV-associated sexual behaviors and the efficacy of prevention interventions in adolescents at-risk for HIV infection: what works and what doesn't work? Psychosom Med 2008 2008(70):598-605

62. Ethier KA, Niccolai LM, Lewis JB, Ickovics JR: Adolescent women underestimate their susceptibility to sexually transmitted infections. Sex Transm Infect 2003, 79:408-411. doi: 10.1136/sti.79.5.408.

63. Ford CA, Jaccard J, Millstein SG, Bardsley PE, Miller WC: Perceived risk of chlamdial and gonococcal infection among sexually experienced young adults in the United States. Perspect Sex Reprod Health 2004, 36(6):258-264.

64. Maurier WL, Northcutt HC: Self-reported risk factors and perceived chance of getting HIV/AIDS in the 1990s in Alberta. Can J Public Health 2000, 91(5):340-344.

65. Newman PA, Zimmerman MA: Gender differences in HIV-related sexual risk behavior among urban African American youth: a multivariate approach. AIDS Educ Prev 2000, 12(4):308-325.

doi:10.1186/1471-2458-13-1126

Cite this article as: Sychareun et al:: Risk perceptions of STIs/HIV and sexual risk behaviours among sexually experienced adolescents in the Northern part of Lao PDR. BMC Public Health 2013 13:1126.

\section{Submit your next manuscript to BioMed Central and take full advantage of:}

- Convenient online submission

- Thorough peer review

- No space constraints or color figure charges

- Immediate publication on acceptance

- Inclusion in PubMed, CAS, Scopus and Google Scholar

- Research which is freely available for redistribution 